\title{
Modelling of electron trajectories inside SEM chamber concerning mirror effect phenomenon
}

\author{
Hassan N. Al-Obaidi ${ }^{1}$, Imad H. Khaleel ${ }^{2}$ \\ ${ }^{1}$ Department of Physics, College of Education, Al-Mustansiriyah University, Baghdad, Iraq. \\ ${ }^{2}$ Department of Physics, College of Education (Ibn Al-Haitham), Baghdad University, Baghdad, \\ Iraq. \\ E-mail: imad_hadi@yahoo.com
}

\begin{abstract}
A computational investigation is carried out to describe the behaviour of reflected electrons upon a charged insulator sample and producing mirror effect images. A theoretical expression for the scanning electron path equation is derived concerning Rutherford scattering and some electrostatic aspects. The importance of the derived formula come from its correlation among some of the most important parameters that controls the mirror effect phenomena. These parameters, in fact, are the trapped charges, incident angle and the scanning potential which investigated by considering its influences on the incident electrons. A pervious experimental operation requirements are adopted for operating the introduced expression. However, the obtained results are almost encouraged for sense of mirror effect.
\end{abstract} Key words insulators, charge trapping, electron mirror effect .

\section{Article info}

Received: Sep. 2012

Accepted: Apr. 2013

Published: Sep. 2013

\section{نمذجة مسارات الاكترون داخل حجرة المجهر الاكتروني الماسح تبعاً لظاهزة التأثير المرآتي \\ حسن نوري العبيدي'، عماد هادي خليل2$$
\text { 1ققسم الفيزياء، كلية التربية، الجامعة المستتصرية، بغداد، العر اق. }
$$$$
\text { 2قسم الفيزياء، كلية التربية ابن الهيثم، جامعة بغداد، بخداد، العراق. }
$$

الخلاصة

اجريت دراسة حاسوبية لوصف سلوك الآكترونات المنعكسة عن عينة العازل المشحون وانتاج صور التأثير المرآتي. تم

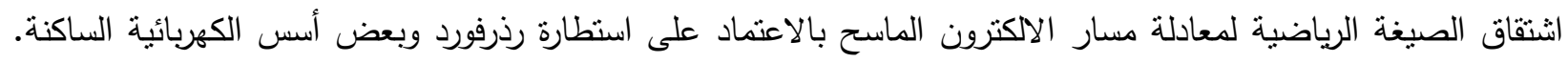

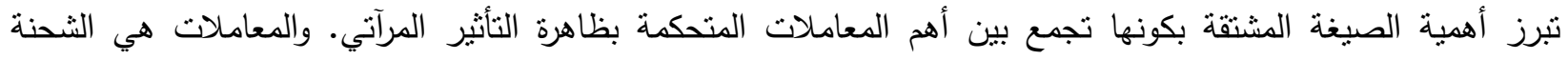

المقيدة، زاوية السقوط، وجها المسح. وتم دراسة تأثير هذه العوامل على الالكترونات الساقطة. وتم اعتماد منطلبات التشغيل

التجريبية لتتفيذ الصيغة المقدمة. وقد كانت النتائج المستحصلة مشجعة لاستعمال الصيغة الدقدمة لهحاكات مسار الالكترون

بمنظور الثأثير المرآتي. 


\section{Introduction}

One of the biggest problems with use of Scanning Electron Microscope (SEM) for exploring insulating materials at conventional accelerating voltage is their tendency to accumulate negative charges and consequently to repel the incident beam during their observation [1]. These effects experimentally known for the (SEM) in the early 1970's and called as "charging effect" [2] and so much effort has been devoted to make sure that this effect dose not occur since it is detrimental of the image quality. Two decades later, Gressus et al. developed an experimental method consist of charging the insulator by bombarding it with an electron beam and then observed a mirror image of the (SEM) chamber formed by low energy scanning electrons and provide information about the sample dielectric properties $[3,4]$.

The Scanning Electron Microscope Mirror (SEMM) method is frequently employed in study of electrical properties (charge trapping/detrapping, flashover, and electric breakdown) of insulating material (polymers, ceramics, ...) and it has much interest because of its importance in technology and industry [5-8].

\section{The Electron Mirror Effect}

Electron Mirror Effect (EME) is a physical phenomena inside the chamber of (SEM) when the irradiation electron beam scans a dielectric sample. For seemingly inexplicable reasons, an image of the interior of the (SEM) appears instead of the image of the surface of interest [9]. However, the physics behind mirror effects is that when an insulating sample is irradiated in a first phase in a (SEM) at a high voltage, Negative charges will trapped in the insulator sample during the injection process. The trapped charges produce an electric field in the vacuum chamber of the (SEM). If the sample is observed later (in a second phase), with a lower energy electron beam, the electric field can be strong enough to deflect the probing electron in the same manner as a convex mirror dose with light [10].

Alternatively, the effect of the trapped charge on incoming electrons is repulsion, so that electrons with sufficiently small kinetic energy are reflected back to different points of the (SEM) chamber, depending on the incoming direction and beam parameter [11]. The consequent interaction between these electrons and various instruments, objects, and the inner walls of the (SEM) chamber can generate secondary electrons, which characteristics depend on the chamber materials and primary electron energy. The secondary electrons are then detected by the active detector within the chamber to form the mirror image of the (SEM) chamber itself as illustrated schematically in Fig.1. Accordingly, the path of electrons during its travel, since they emerges from the column till the detector may controls and influenced by several or many physical and/or geometrical parameters. Consequently, it is of more interest to explore these parameters concerning mirror images and its correlation with sample dielectric characteristics, which is the purpose of this work.

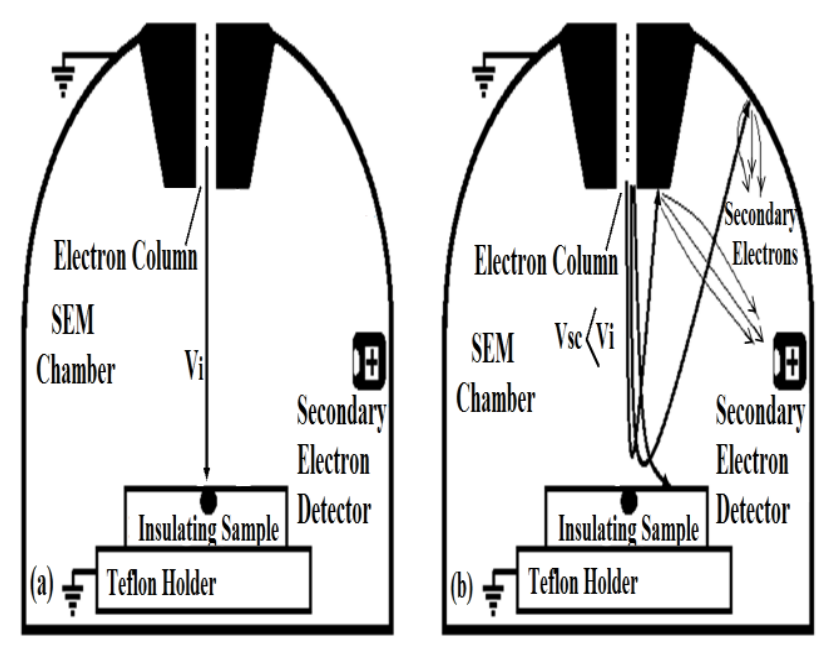

Fig.1: Schematic illustration of the charging process (a) and the SEM mirror image formation (b). 


\section{Theoretical Aspects}

Rationally one may regard that the trapped charge $Q_{t}$ is a point charge which is stationary at an arbitrary point like $\mathrm{C}$ and a probing electron $e$ approaching it along the line $A B$ as shown in Fig.2. Since the trapped charge embedded in a dielectric sample with a relative permittivity $\varepsilon_{\mathrm{r}}$ is a same as that due to a charge $2 Q_{t} /\left(\varepsilon_{r}+1\right)$ in free space [12]. Therefore, the Coulomb's repulsion force between the probing electron and the trapped charge take the form;

$$
\mathrm{F}=\frac{\lambda \mathrm{e} \mathrm{Q}_{\mathrm{t}}}{\mathrm{r}^{2}}
$$

where $r$ is the distance of the probing electron from the trapped charge, $\lambda$ is a constant defined by $\lambda=1 /\left[2 \pi \varepsilon_{o}\left(\varepsilon_{r}+1\right)\right]$ and $\varepsilon_{\mathrm{o}}$ is permittivity of free space.

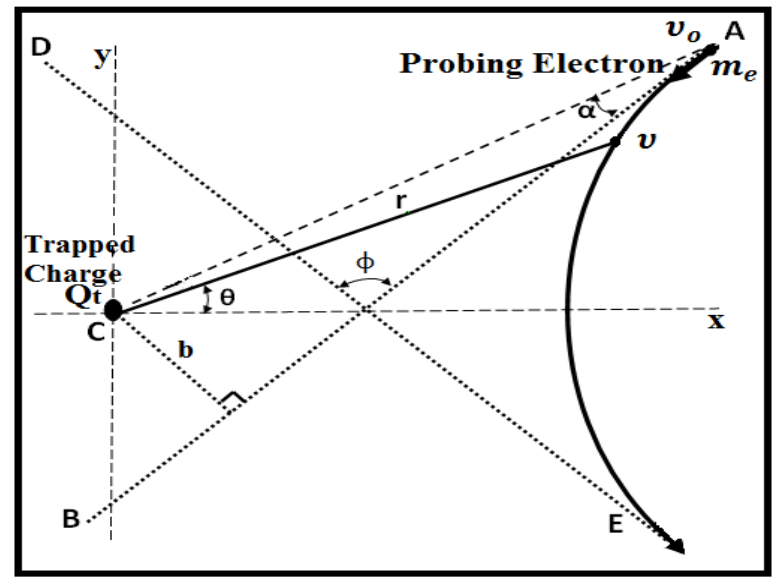

Fig.2: Geometrical illustration for the derivation of the electron path equation.

To derive a close-real expression for the path of the probing electron, the polar coordinates will be chooses with a trapped charge at the point $\mathrm{C}$. The acceleration of the probing electron can be resolved with two components, one along the radius $\left(a_{r}\right)$ and the other being transverse to the radius $\left(a_{\Theta}\right)$. Since the force of repulsion is along the radius (central force) then the equations of motion, in radial and transverse direction respectively, can be expressed with the aid of Newton's second law as follows;

$$
\begin{aligned}
& m_{e}\left[\frac{d^{2} r}{d t^{2}}-r\left(\frac{d \theta}{d t}\right)^{2}\right]=\frac{\lambda e Q_{t}}{r^{2}} \\
& m_{e}\left[r \frac{d^{2} \theta}{d t^{2}}+2 r\left(\frac{d r}{d t}\right)\left(\frac{d \theta}{d t}\right)\right]=0
\end{aligned}
$$

where $m_{e}$ is the probing electron rest mass, keeping in mind the relativistic effect are considered to be negligible since this is the usual case under the typical SEM operating condition. Actually, the last equation expresses the principle of conservation of angular momentum (L) and can be written in the form;

$$
\mathrm{m}_{\mathrm{e}} \mathrm{r}^{2} \frac{\mathrm{d} \theta}{\mathrm{dt}}=\text { const. }=\mathrm{L}
$$

But the angular momentum is defined as;

$$
\mathrm{L}=\mathrm{rm}_{\mathrm{e}} \mathrm{v}_{\mathrm{o}} \sin \alpha=\mathrm{m}_{\mathrm{e}} \mathrm{v}_{\mathrm{o}} \mathrm{b}
$$

The symbol (b) appeared in the last equation represents the perpendicular distance of the trapped charge from the tangent to the path of the probing electron, $\alpha$ and $v_{o}$ are the incident angle and initial velocity of probing electron. In fact the term of initial velocity refers to velocity of probing electron when it just leaves the column diaphragm of the SEM apparatus.

It is of more interest to express electron path in terms of $(\theta)$ rather than the time, because the charging and so imaging processes occurs in ultra short time. So the time dependent will be eliminate from equations of motion with aid of equations (4, $5)$. In order to achieve such a task it is helpful to introduce new dependent variable like $(\mathrm{u})$ which relate to the original path function (r) through the formula; $(u=1 / r)$. Thus, the using of chain rule with new variable (u) may lead to convert equation (2) to the following form;

$$
\frac{\mathrm{d}^{2}}{\mathrm{~d} \theta^{2}}\left\{\mathrm{u}+\frac{\lambda \mathrm{Q}_{\mathrm{t}}}{2 \mathrm{~V}_{\mathrm{sc}} \mathrm{b}^{2}}\right\}+\left\{\mathrm{u}+\frac{\lambda \mathrm{Q}_{\mathrm{t}}}{2 \mathrm{~V}_{\mathrm{sc}} \mathrm{b}^{2}}\right\}=0
$$

Equation (6) is a second orderhomogenous differential equation with 
constant coefficients. So it admit a solution of the form;

$$
\mathrm{u}=\mathrm{A} \cos \left(\theta-\theta_{\mathrm{o}}\right)-\frac{\lambda \mathrm{Q}_{\mathrm{t}}}{2 \mathrm{~V}_{\mathrm{sc}} \mathrm{b}^{2}}
$$

where $\mathrm{A}$ and $\theta_{\mathrm{o}}$ are constants. However, by a proper choice for the axis, the phase angle can be set equal to zero. Furthermore, by setting $\left(\varepsilon=2 A V_{s c} b^{2} / \lambda Q_{t}\right)$ the probing electron path equation can be written as follows;

$$
\mathrm{u}=\frac{1}{\mathrm{r}}=-\frac{\lambda \mathrm{Q}_{\mathrm{t}}}{2 \mathrm{~V}_{\mathrm{sc}} \mathrm{b}^{2}}(1-\varepsilon \cos \theta)
$$

It seen that, path's equation represent a form of equations of a conic section in polar coordinate where $\varepsilon$ is the eccentricity of this conic section. Indeed, when $\varepsilon$ is greater than unity $(\varepsilon>1)$, the conic section will be a hyperbola [13]. Furthermore, equation (8) declare that for a such operational parameters, the probing electron path can be determined once $\varepsilon$ and $\theta$ are known, for such details will be discussed in the following paragraphs.

The eccentricity of the probing electron path can be determined with the aid of the principle of conservation of energy. The energy conservation law requires that the total energy of the incoming electron remains constant since the (SEM) chamber is evacuated and the probing electron deflected without reaching the insulator surface. Thus the total energy for probing electron can be written as;

$$
\mathrm{eV}_{\mathrm{sc}}=\frac{1}{2} \mathrm{~m}_{\mathrm{e}} \mathrm{v}^{2}+\frac{\lambda \mathrm{e} \mathrm{Q}_{\mathrm{t}}}{\mathrm{r}}
$$

where the second term refers to the potential energy of the probing electron at any point along its path, since it emerges from the column diaphragm till its reflection away from sample. The velocity of probing electron $v$ can be resolved into pair of components, one along the radius $\left(\dot{r} \hat{a}_{r}\right)$ and the other is transverse to the radius $\left(r \dot{\theta} \hat{a}_{\theta}\right)$. Then, by using chain rule, one may get;

$$
v^{2}=\left(\frac{d r}{d t}\right)^{2}+\left(r \frac{d \theta}{d t}\right)^{2}=\left[\left(\frac{d r}{d \theta}\right)^{2}+r^{2}\right]\left(\frac{d \theta}{d t}\right)^{2}
$$

The differentiation of both sides of equation (8) can easily be deduced to be as in the following form;

$$
\frac{\mathrm{dr}}{\mathrm{d} \theta}=\frac{\lambda \mathrm{Q}_{\mathrm{t}} \mathrm{r}^{2}}{2 \mathrm{~V}_{\mathrm{sc}} \mathrm{b}^{2}} \varepsilon \sin (\theta)
$$

Now, by substitute the values of $r^{2}, d \theta / d t$ and $\mathrm{dr} / \mathrm{d} \theta$ according to equations ( 8,4 and $11)$ respectively in equation (10) yields;

$$
v^{2}=\left(\frac{e \lambda^{2} Q_{t}^{2}}{2 m_{e} V_{s c} b^{2}}\right)\left[1+\varepsilon^{2}-2 \varepsilon \cos (\theta)\right]
$$

Using this form of $v^{2}$ in equation (9) with aid of that of $r$ expressed in equation (8) one may obtain the final form of eccentricity for the case under consideration as in the formula below;

$$
\varepsilon=\left[1+\left(\frac{2 \mathrm{~V}_{\mathrm{sc}} \mathrm{b}}{\lambda \mathrm{Q}_{\mathrm{t}}}\right)^{2}\right]^{1 / 2}
$$

It can be seen that the eccentricity is always greater than unity and hence the path followed by probing electrons is definitely hyperbola curve with the trapped charge at the focus outside the branch of this curve.

The asymptote $\mathrm{AB}$ represents the direction of the initial velocity of the probing electron when it leaves column bore, and the second asymptote DE represents the direction of the final velocity of the probing electron, see Fig.2. The angle between the two asymptotes can be deduced by means of modified Rutherford formula as in the following relation [14];

$$
\tan \left(\frac{\varphi}{2}\right)=\frac{\lambda Q_{t}}{2 V_{s c} b}
$$

However, the parameter $\theta$ may regarded to be an independent variable in order to 
determine the probing electron path, which their owns values are controlled by the condition $\quad\left(\frac{\pi}{2}-\frac{\varphi}{2}-\alpha\right) \leq \theta \leq-\left(\frac{\pi}{2}-\frac{\varphi}{2}-\alpha\right)$ as can realized from Fig.2.

\section{Application and Discussion}

For the implementation of simulation calculation for a probing electron the eccentricity of the hyperbola path is computed firstly, for a specific operational parameters $\left(V_{s c}, Q_{t}, b, \varepsilon_{r}\right)$, with aid of equation (13). Thereafter, the scattering angle $\varphi$ is determined by means of equation(14). Hence the probing electron path can be obtained by using of equation(8). Actually, several computational process is followed to shifting the axes so as to be like the one appears in figure 3, because electrons at the beam centre leaves parallel to the optical axes of the column. In order to gives the above simulation a practical realization, results of other author [15] is adopted to achieve such a task.

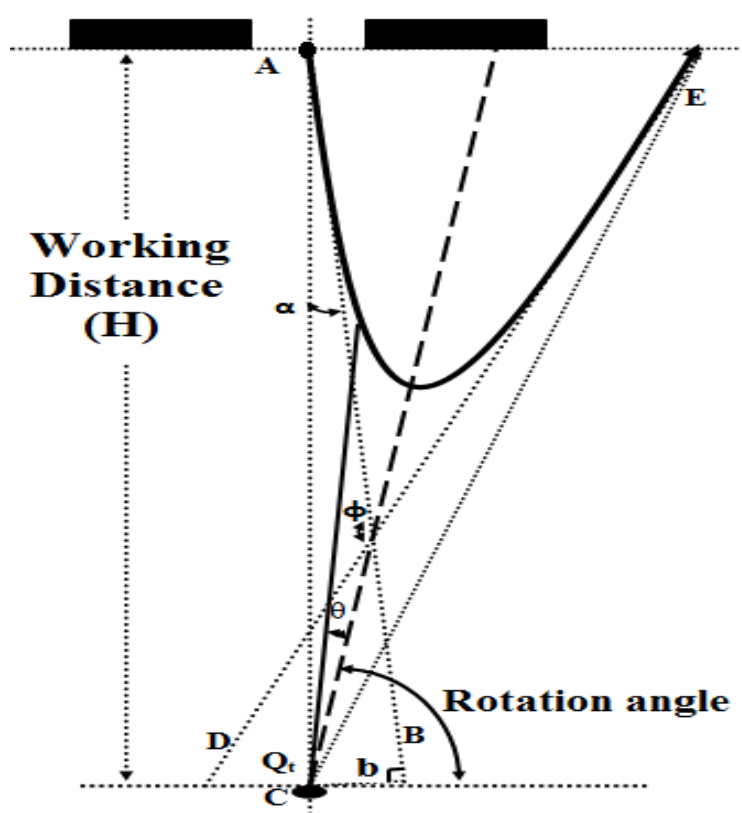

Fig.3: A Schematic diagram for a probing electron trajectory and the shifting of axis.

Fig.4a shows several electron mirror images which are imported from reference[15]. According to this reference, each of these images is obtained at different irradiation time for a PET samples. Where, these samples are irradiated for different periods of time by an electron beam accelerated up to $\mathrm{V}_{\mathrm{i}}=20 \mathrm{kV}$ with a current of $\mathrm{I}_{\mathrm{i}}=1.1 n A$. For each period of time, the value of diaphragm diameter (d) is measured by means of the electron mirror images that obtained at a scanning potential $\mathrm{V}_{\mathrm{sc}}=300 \mathrm{~V}$. So the trapped charge at each sample is calculated with aid of equation $\mathrm{Q}_{\mathrm{t}}=19.609 \times 10^{-7} \mathrm{~d}$ regarding the dielectric constant for PET material to be 3.43 . Thus, the determined $Q_{t}$ versus its own irradiation time are as in the Table-I.

Table-I: Trapped charges as a function of irradiation time see reference [15].

\begin{tabular}{|l|c|c|c|c|}
\hline $\mathrm{t}(\mathrm{sec})$ & 15 & 45 & 90 & 300 \\
\hline $\mathrm{Q}_{\mathrm{t}}(n C)$ & 0.2069 & 0.3019 & 0.3723 & 0.4448 \\
\hline
\end{tabular}

Fig. $4 \mathrm{~b}$ represents the probing electron paths along the radial distance, which belong to each image for several incident angles $\alpha$. Several important remarks could be recorded from theses graphs, however, the most important ones are the following two observations. A part from the decreases in the scattering angle $\varphi$ for the curves of different incident angle $\alpha$ for the same image, it is seen that $\varphi$ increases for the counterpart curves of a same $\alpha$ at the different images. In fact such a result explain obviously why the field of view decreases with the increases of the trapped charges value. For more clarity, Fig.5 reveals how a probing electron of a same incident angle $\left(\alpha=0.6^{\circ}\right)$ can scans more areas, from the chamber ceiling whenever the concentration of the accumulated charges at the sample under consideration decreases and vice versa. 


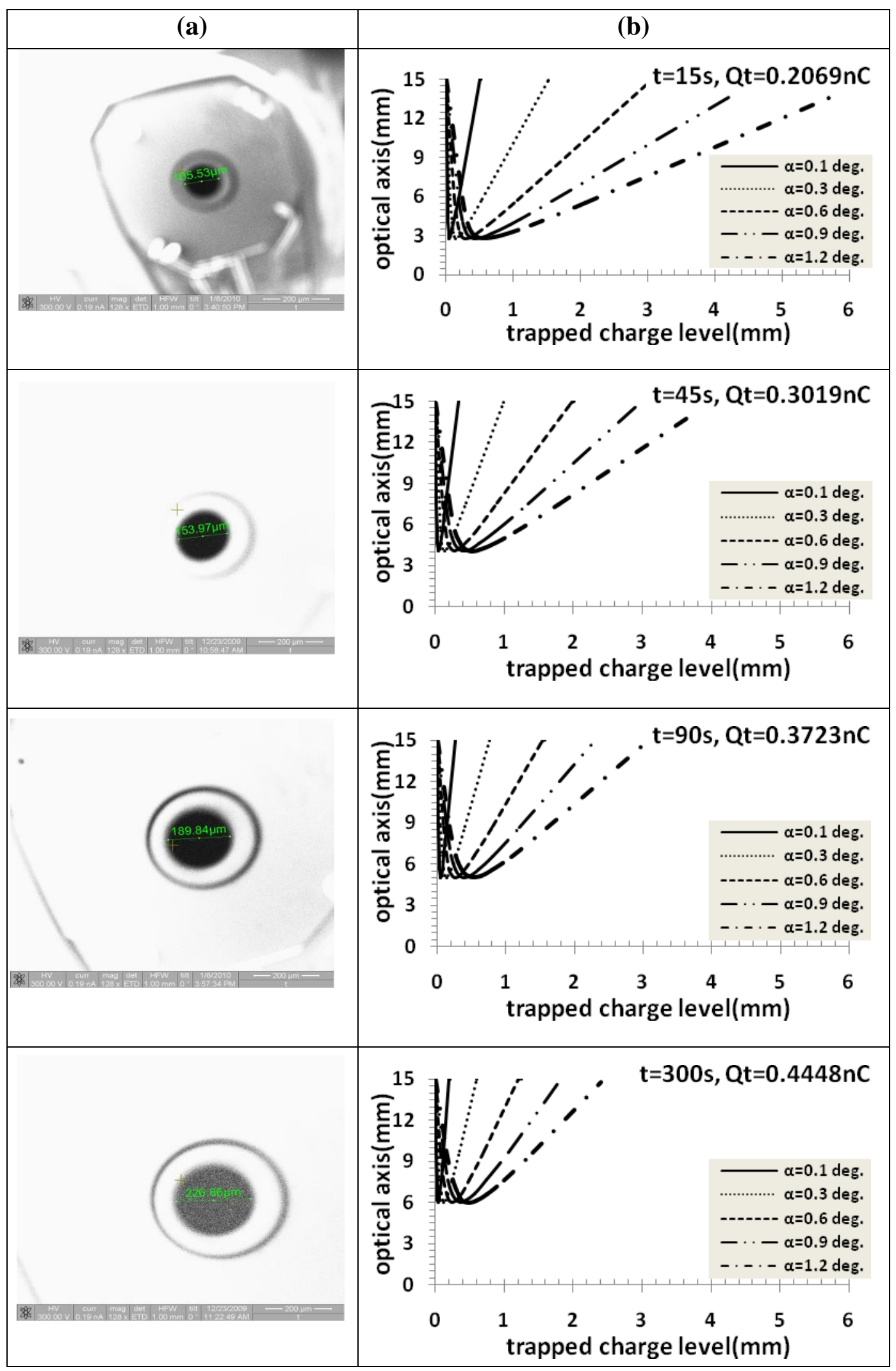

Fig. 4: (a) Electron mirror images imported from reference [15] and (b) their corresponding probing electron paths according to present work. 


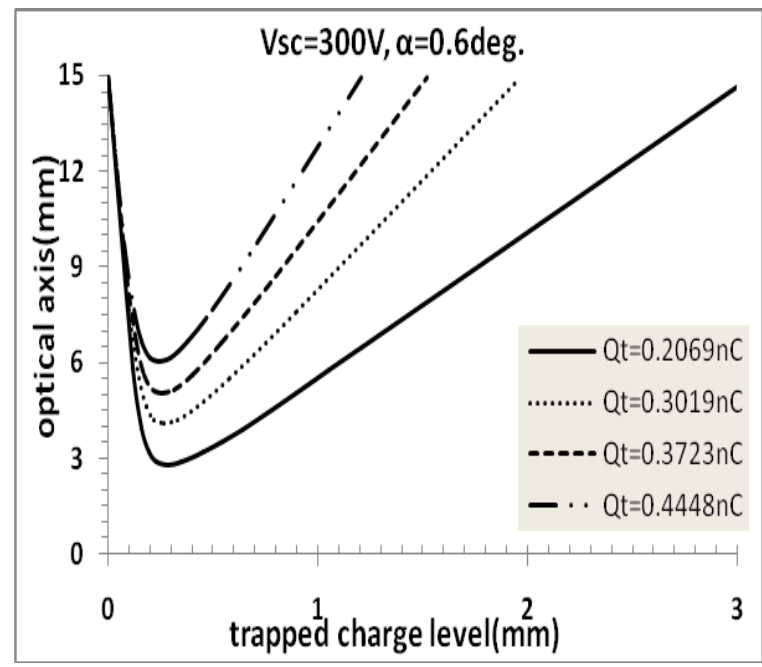

Fig.5: Different probing electron paths of a same incident angle reflects to different areas.

The second observation, however, is that the reflection in electron probing paths gradually shifted away from the sample as the trapped charges increases. Fig.6 clarifying such a result, where one may observe the reflection point height of path relative to the sample stage increases as $\mathrm{Q}_{\mathrm{t}}$ increases. Thus this behaviour may interpreted why the images seems to be approaching to the column whenever $\mathrm{Q}_{t}$ get further increases.

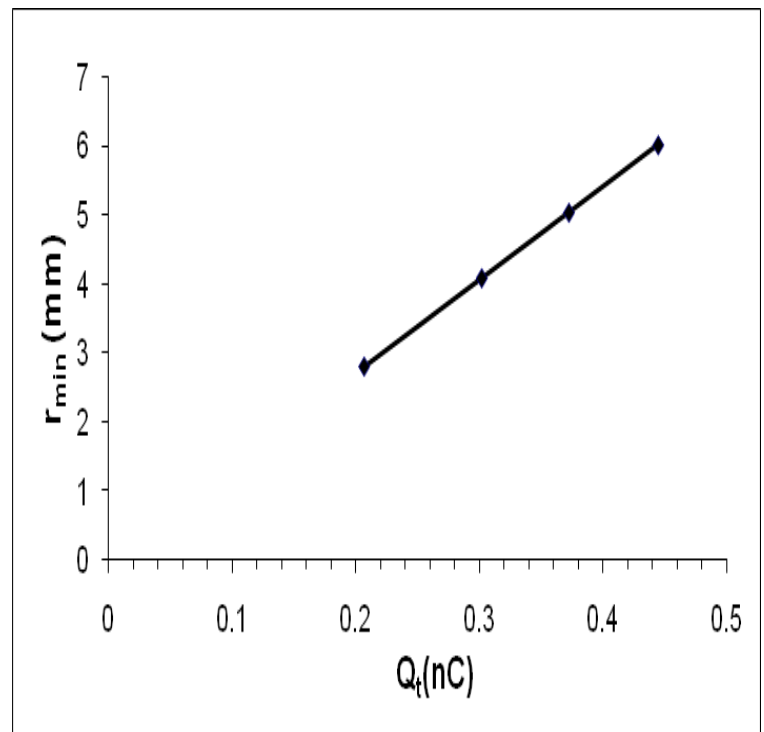

Fig.6: Variation of the reflection point with trapped charge.

\section{Conclusions}

Results of the presented approach for determination of the probing electron path, throughout the SEM chamber, shows clearly an excellent interpretation for the deduced electron mirror images. Additionally it gives an encourage ambitions for further advanced investigation for electron mirror phenomena. Furthermore, the model presented in this work may revised in such away the trapped charge can evaluated without needs to use ideas of Rutherford's scattering.

\section{References}

[1] E. I. Rau, S. Fakhfakh, M. V. Andrianov, E. N. Evstafeva, O. Jbara, S. Rondot, and D. Mouze: Nuc. Ins. Meth. Phys. Res., B266, (2008) 719-729.

[2] D. R. Clark, and P. R Stuart: j. Phys. E: Sci. Ins., 3 (1970) 705-707.

[3] C. Le Gressus, F. Valin, M. Henriot, M. Gatier, and J. P. Duraud, J. Appl. Phys., 69, 9 (1991) 6325-6333.

[4] M. Milani, C. Savoia, and D. Bigoni: Proceeding of ITP2009 Interdisciplinary Transport Phenomena VI: Fluid, Thermal, Biological, Materials and Space Sciences, Italy,(2009).

[5] S. Fakhfakh, and O. Jbara: Annual Report Conference on Electric Insulation and Dielectric Phenmena, IEEE, (2009), pp. 441-445.

[6] M. L. Hattali, N. Mesrati, and D. Treheux: J. Eur. Ceram. Soc. 32(2012)717725.

[7] A. G. Sutipto, R. Jufriadi , R. Muhida, and E. Y. Adesta: World Academy of Science, Engineering and Technology, 53(2009) 8-11.

[8] J. Liebault, D. Moya-Siesse, J. Bernardini, and G. Moya: Surf. Interface Anal., 34(2002) 668-671.

[9] M. Milani, H. N. Abdul-Wahab, T. H. Abbood, C. Savoia, and F. Tatti: Micr.: Scie., Tech., Appl. and Edu.(2010), pp 17411754. 
[10] N. Ghorbel, and A. Kallel: 2010 Annual Report Conference on Electrical Insulation and Dielectric Phenomena., IEEE(2010), pp. 1-4.

[11] H. N. Al-Obaidi, F. A. Al-Saymary, and A. A. Ali: Proc. Summ. Scho., Sept. 8th Oct. $8^{\text {th }}$ (2008), Milano, Italy.

[12] J. D. Jackson, Classical Electrodynamics, John Wiley, New York, (1999) 3rd ed., Chap.1 and 4.
[13] D. C. Howard, Orbital Mechanics for Engineering Students, ButterworthHeinemann publications, USA, (2010) $2^{\text {nd }}$ ed., Chap. 2.

[14] R. Coelho, B. Aladenize, B. Garros: IEEE Trans. Electr. Insul., 6.2 (1999) 202210.

[15] T. H Abbood., Ph.D. Thesis: College of Education, University of Al-Mustansiriyah, Baghdad, Iraq, (2011). 